\title{
IMPLEMENTASI E-CERDAS CERMAT PADA LOMBA ASAH TERAMPIL GAPOKTAN BUDHI LUHUR
}

\author{
K.O. Saputra ${ }^{1}$, G. Sukadarmika ${ }^{2}$, M. A. Suyadnya ${ }^{3}$, and N. P. Sastra ${ }^{4}$
}

\begin{abstract}
ABSTRAK
Tujuan dari pengabdian kepada masyarakat yang dilakukan di Desa Katung, Kecamatan Kintamani, Kabupaten Bangli ini adalah untuk mengimplementasikan sistem e-cerdas cermat pada lomba asah terampil yang akan dilakukan oleh Gabungan Kelompok Tani (Gapoktan) Budhi Luhur. Target khusus yang ingin dicapai dalam kegiatan pengabdian ini adalah untuk meningkatkan kualitas kegiatan asah terampil di Gapoktan Budhi luhur, yang sebelumnya masih bersifat konvensional, menjadi sebuah acara yang dikemas menarik dalam balutan teknologi informasi melalui sistem E-cerdas cermat. Awal-awal simulasi adalah kondisi yang sangat berat, karena calon peserta merasa akan kesulitan dalam menggunakan perangkat laptop/handphone dalam melaksanakan lomba. Namun setelah mulai merasa familiar para peserta merasa sangat tertarik, tertantang, dan merasa ingin lagi merasakan sensasi lomba dengan sistem E-cerdas cermat.
\end{abstract}

Kata kunci : E-learning, e-exam, Gapoktan Budhi Luhur, Desa Katung, e-cerdas cermat

\begin{abstract}
The community service program held in Katung village aims to implement e-cerdas cermat to "Lomba asah terampil" Gapoktan Budhi Luhur. Previously, Gapoktan Budhi Luhur has conducted "Lomba asah terampil" twice. However, their program was conventional. Therefore, to improve its quality, our sistem, E-Cerdas Cermat is suitable to be implemented. At the beginning, when we perform simulation for the participants, it was such a bad time, as the participants felt hard to use notebook or mobile phone when answering the quizzes. However, after getting more familiar, participants fell interesting, challenging, and the most important thing is they want to play and feel the sensation again.
\end{abstract}

Keywords: E-learning, e-exam, Gapoktan Budhi Luhur, Desa Katung, e-cerdas cermat.

\section{PENDAhuluan}

Desa Katung terletak di Kecamatan Kintamani Kabupaten Bangli. Di Desa Katung, terdapat berbagai macam organisasi yang tumbuh dan berkembang dengan pesat, seperti Sekaa Teruna, Kelompok Tukang Ukir, Kelompok Wanita Tani, dan Kelompok Tani Ternak. Khusus Kelompok Tani Ternak, 6 kelompok tani dinaungi oleh sebuah organisasi bernama Gabungan Kelompok Tani (Gapoktan) Budhi Luhur.

Gapoktan Budhi Luhur dan anggota-anggotanya selain melakukan kegiatan dibidang pertanian dan peternakan juga sering melakukan kegiatan-kegiatan untuk meningkatkan keakraban sesama anggota maupun dengan masyarakat lainnya. Salah satu kegiatannya adalah lomba asah terampil untuk menguji pengetahuan dan skill dibidang pertanian.

\footnotetext{
${ }^{1}$ Staf Pengajar Prodi Teknik Elektro Fakultas Teknik Universitas Udayana, okasaputra@unud.ac.id

${ }^{2}$ Staf Pengajar Prodi Teknik Elektro Fakultas Teknik Universitas Udayana, sukadarmika@unud.ac.id

${ }^{3}$ Staf Pengajar Prodi Teknik Elektro Fakultas Teknik Universitas Udayana, arsa.suyadnya@unud.ac.id

${ }^{4}$ Staf Pengajar Prodi Teknik Elektro Fakultas Teknik Universitas Udayana, a@unud.ac.id
} 
Uji pengetahuan pada kegiatan asah terampil Gapoktan Budhi Luhur masih berbentuk konvensional. Pertanyaan-pertanyaan disampaikan secara lisan dimana para peserta akan rebutan menjawab dengan memukul kentongan. Untuk keakraban, sistem ini tidak menimbulkan permasalahan, dimana kadang tidak jelas siapa sebenarnya yang berhak menjawab, karena suara kentongan yang satu dengan lainnya susah dibedakan. Namun, lomba tetaplah lomba, dimana kecepatan menjawab dan kebenaran jawaban mutlak untuk menentukan pemenang. Soal-soal yang dipergunakan pada saat lomba juga masih berbentuk pertanyaan lisan yang kebenaran jawabannya ditentukan secara subyektif oleh para juri. Sebuah sistem uji pengetahuan dengan kemasan baru, yang mengedepankan teknologi namun tetap mempertahankan aspek-aspek keakraban sangat diperlukan untuk mempertahankan tradisi kegiatan asah terampil Gapoktan Budhi Luhur, bahkan untuk semakin membuat para pesertanya tertarik untuk menanti kegiatan-kegiatan selanjutnya.

\section{METODE PELAKSANAAN}

Untuk mencapai tujuan dalam meningkatkan lomba asah terampil Gapoktan Budhi Luhur, pengabdian kepada masyarakat ini menggunakan metode simulasi dan pendampingan seperti pada gambar 2.1. Simulasi harus dilakukan karena peserta lomba meskipun dalam keseharian sudah terbaisa menggunakan perangkat laptop dan mengakses website tetap perlu diberikan tutorial dalam menjawab soal-soal. Hal ini dikarenakan soal-soal yang diberikan berbentuk game yang perlu penjelasan spesifik agar bisa menggunakan dengan fasih.
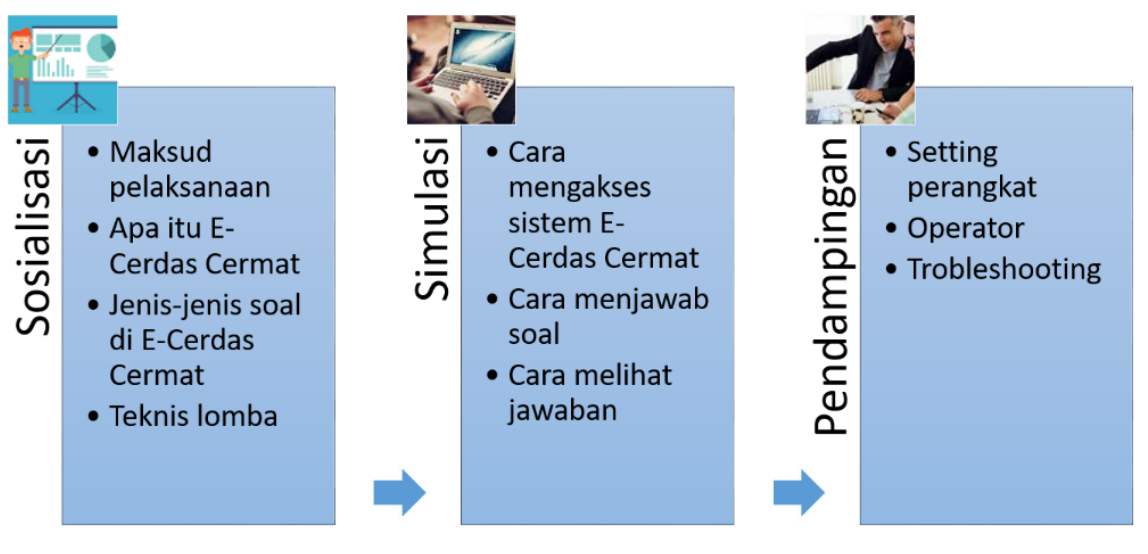

Gambar 2.1. Metode pelaksanaan

\section{HASIL DAN PEMBAHASAN}

Lomba asah terampil dengan menggunakan sistem E-Cerdas Cermat diikuti oleh 12 peserta yaitu: Sekaa Teruna Putra, Sekaa Teruna Putri, Sekaa Gong, Sekaa Pecalang, PKK, Poktan Budhi Tunggal, Poktan Wangun Sari, Poktan Stiti Merta Sari, Poktan Arsa Winangun, KSP SMS, dan Poktan Sari Sedana. Lomba asah terampil dibuat dalam 3 babak: 1) Penyisihan, diikuti oleh semua tim; 2) Semi Final, diikuti oleh 6 tim; dan 3) Final, yang diikuti oleh 3 tim. Jenis-jenis game yang digunakan pada Babak Penyisihan adalah "Match the box" dan "Cari Kata". Sedangkan pada Babak Semi Final, dari 6 tim yang lolos, masing-masing tim bertanding dengan satu tim lainnya dalam permainan "Silang vs Bulat". Akhirnya pada Babak Final, 3 tim bertanding untuk menjadi yang tercepat dalam menebak istilah dalam permainan "Tebak Kata". Gambar 3.1 menunjukkan beberapa jenis-jenis game yang dipergunakan pada saat lomba asah terampil, sedangkan bagan pertandingan dan tim-tim yang lolos pada masing-masing babak ada pada Gambar 3.2. 


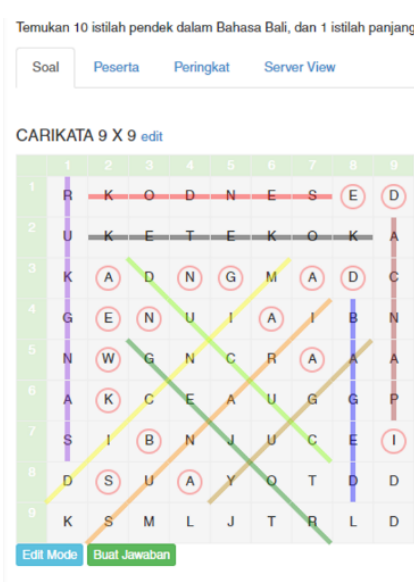

(a)

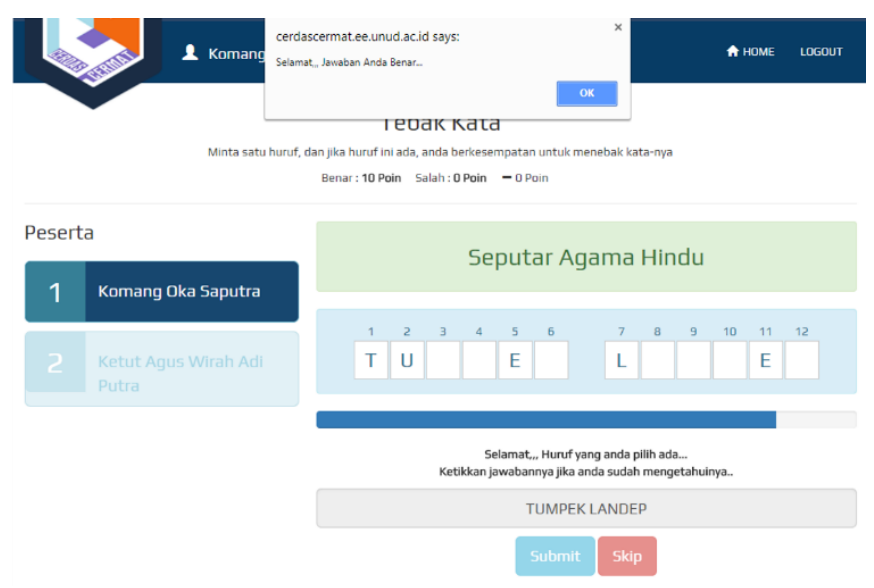

(b)

Gambar 3.1. (a) Soal "Cari Kata" babak penyisihan. (b) Soal "Tebak Kata" babak final

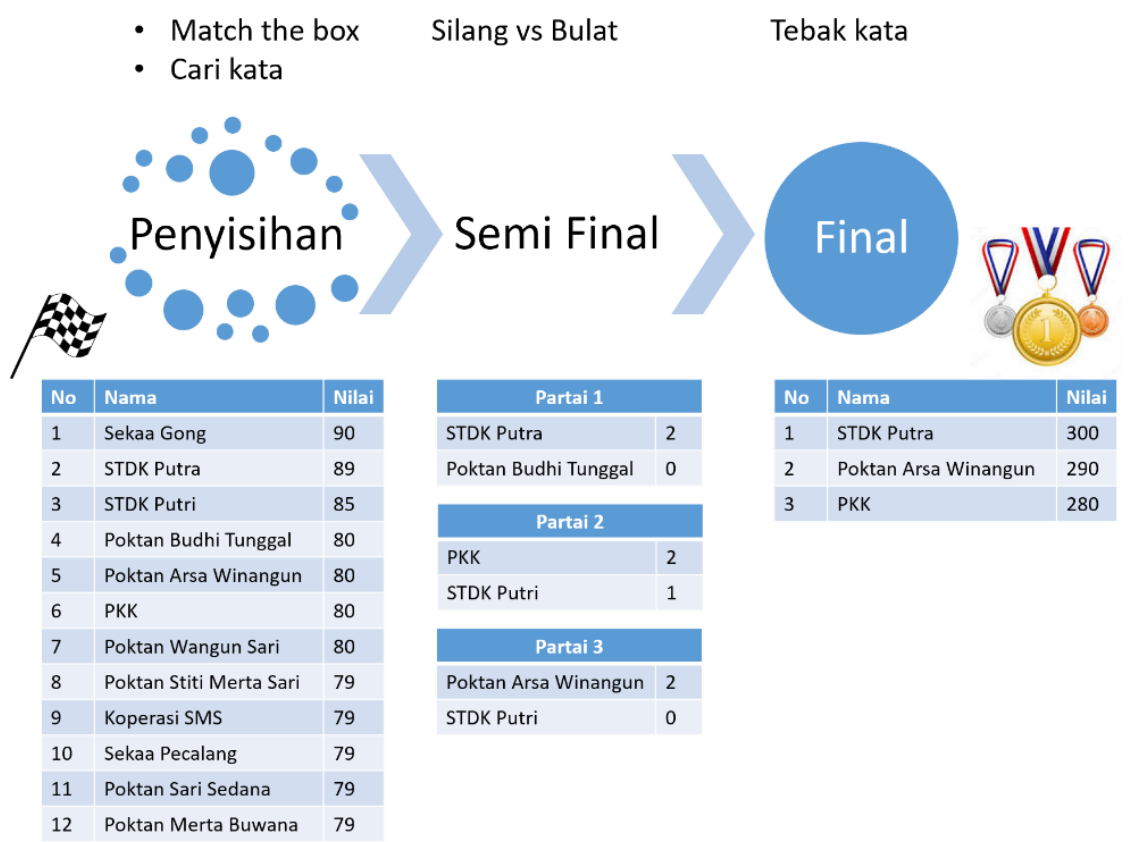

Gambar 3.2. Diagram alir lomba asah terampil

Lomba asah terampil dengan menggunakan sistem E-Cerdas Cermat sudah berhasil dilaksanakan dengan baik. Indikasi berhasilnya program Udayana Mengabdi ini adalah reaksi dari para peserta lomba ketika sedang bermain, ataupun setelah selesai, baik menang ataupun kalah. Para peserta menunjukkan rasa senang, tertarik, dan bahkan merasa tertantang untuk lagi mengikuti kegiatan serupa. Beberapa foto yang bisa ditampilkan dari kegiatan ini bisa dilihat pada Gambar 3.3-3.5. 


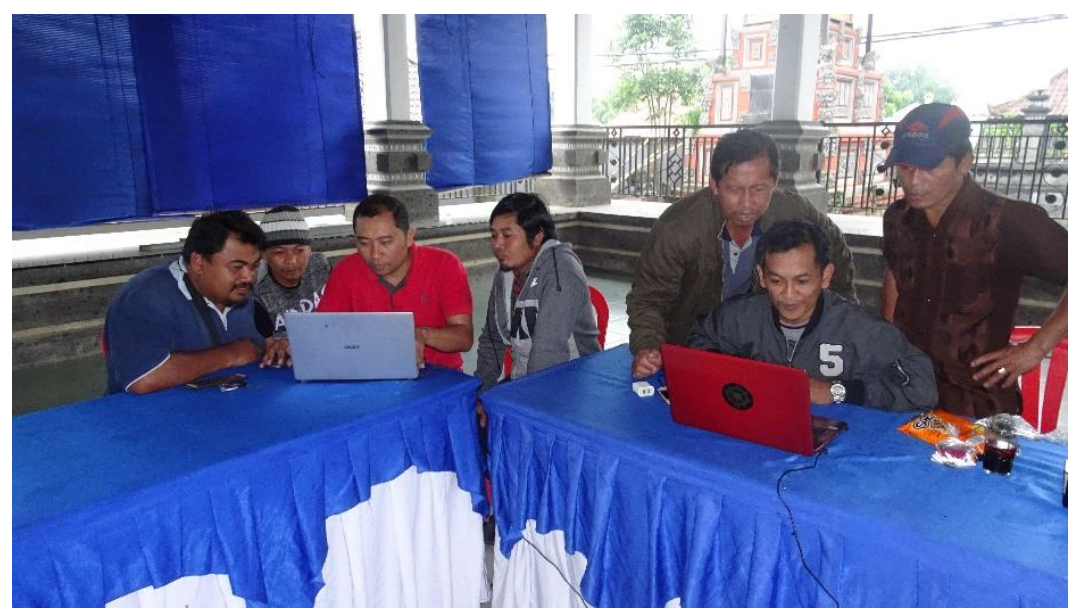

Gambar 3.3. Suasana sosialisasi kegiatan

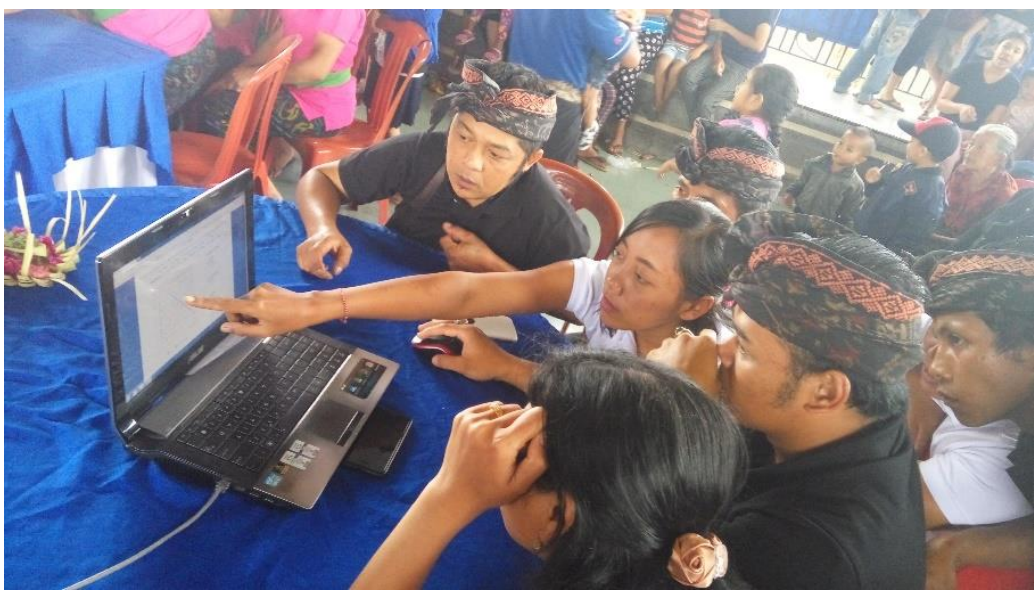

Gambar 3.4. Peserta sedang mengikuti lomba

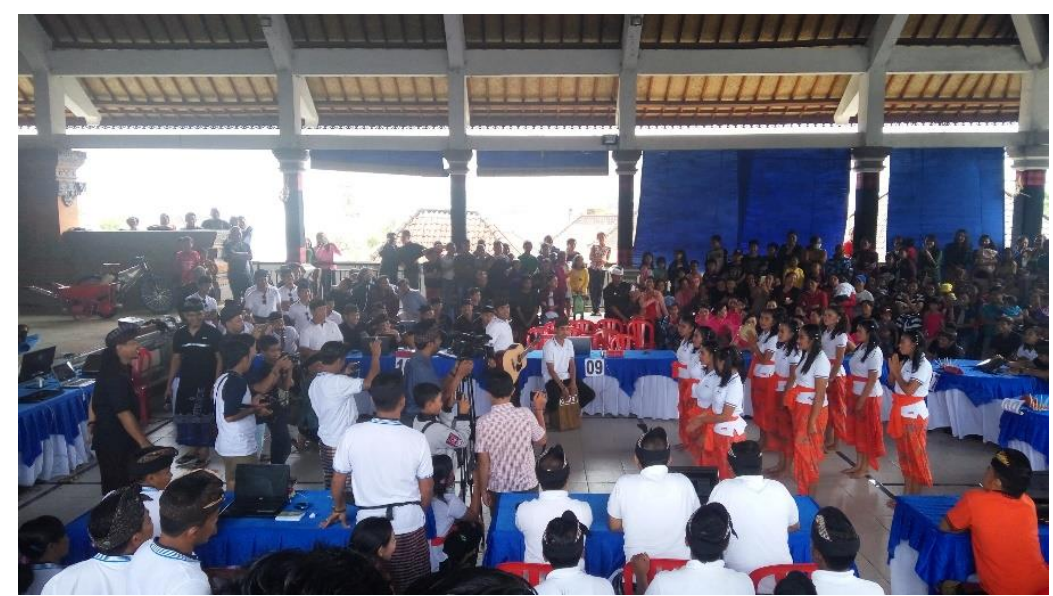

Gambar 3.5. Suasana lomba yang diliput media TV Lokal 


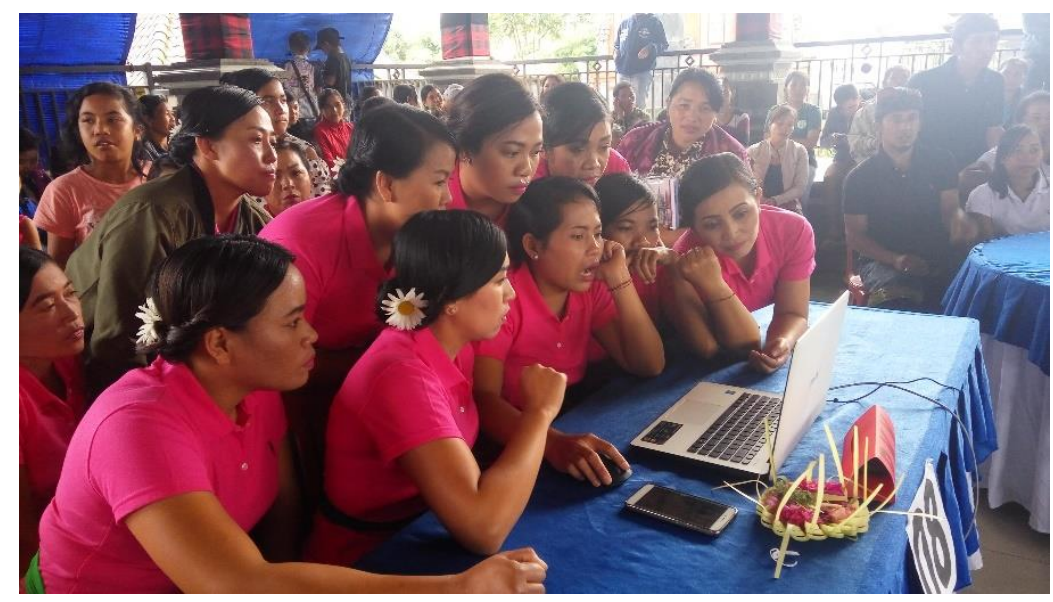

Gambar 3.6. Salah satu peserta (PKK Desa Katung)

\section{KESIMPULAN DAN SARAN}

Melihat dari reaksi para peserta ketika mengikuti lomba asah terampil dengan sistem e-exam ini yang seru, bisa disimpulkan bahwa tujuan untuk meningkatkan level lomba asah terampil Gapoktan Budhi Luhur sudah terlaksana.

Wantilan desa katung sebaiknya memiliki akses internet sehingga memungkinkan melaksanakan easah terampil secara online.

\section{INFORMASI LIPUTAN}

Liputan oleh Bali TV bisa dilihat melalui https://www.youtube.com/watch?v=c1liDBo-

NOY\&feature $=$ share

Liputan 30 menit oleh Dewata TV bisa dilihat melalui

https://www.youtube.com/watch?v=Ocq2bcY2neQ\&t=707s

\section{DAFTAR PUSTAKA}

Andharini Dwi C., Design an Adaptive E-learning Application Architecture Based on IEEE LTSA Reference Model, TELKOMNIKA, Vol.13, No.1, March 2015, pp. 284 289

Budi, Brian Nurjayanti, "Pengembangan Metode Pembelajaran Online Berbasis E-Learning (Studi Kasus Mata Kuliah Bahasa Pemrograman)”, 07 Jurnal Sains Terapan Edisi II Vol-2 (1) : 103 - 113 (2012)

Bates, A. W. Technology, Open Learning and Distance Education. London: Routledge. 1995

Wulf, K. Training via the Internet: Where are We? Training and Development 50 No. 5. (20 September 2006). 